УДК 616.351- $089+616.352-089$

DOI 10.11603/2414-4533.2017.4.8439

() М. П. ЗАХАРАШ ${ }^{1}$, В. В. БАЛИЦЬКИЙ 2,3 , О. Г. КУРИК ${ }^{4}$

Національний медичний університет імені О. О. Богомольця, Київ ${ }^{1}$

Вінницький національний медичний університет імені М. І. Пирогова²

Хмельницька обласна лікарня

Державна наукова установа “Науково-практичний центр профрілактичної та клінічної медицини” Державного управління справами, Київ ${ }^{4}$

\title{
Сучасні методи хірургічного лікування поєднаної патології анального каналу і прямої кишки
}

\begin{abstract}
Актуальність проблеми поєднаної патології анального каналу і прямої кишки досить висока, що на сьогодні зумовлено стрімко зростаючою кількістю проктологічних захворювань, а також відсутністю єдиного підходу щодо хірургічного лікування цієї категорії пацієнтів. Крім того, вивченню даної проблеми присвячена досить незначна кількість публікацій з результатами наукових досліджень. Серед ускладнень після комбінованих операційних втручань на анальному каналі і прямій кишці з приводу їх поєднаної патології найчастіше зустрічаються рубцеві стриктури анального каналу, недостатність анального сфінктера, а також грубі рубцеві деформації періанальних і параректальних ділянок та промежини. Впродовж останнього десятиліття широкого застосування набули “гібридні” операції в лікуванні хронічного геморою III-IV стадії в комбінації з іншою патологією анального каналу і прямої кишки. Вони включають поєднання деартеріалізації гемороїдальних вузлів із мукопексією або латексне лігування гемороїдальних вузлів, їх ліфтинг та мукопексію з видаленням супутньої патології анального каналу. У зв’язку із прогресивним розвитком сучасних технологій у практику колопроктологів почали швидко впроваджуватись такі сучасні методи хірургічного лікування аноректальної патології, як електротермічна система “Liga Sure”, ультразвуковий гармонічний скальпель “Ultra Cision”, лазерні технології в лікуванні анальних тріщин, хронічного геморою та парапроктиту (LHP, FiLaC), плазменний скальпель, біполярна системи “En Seal”, радіохвильовий скальпель “Surgitron”, а також методики LIFT (ligation of intersphincteric fistula tract) та VAAFT (Video Assisted Anal Fistula Treatment), які зменшили тривалість операцій, об’єм крововтрати, інтенсивність больового синдрому, але, на жаль, не позбавили пацієнтів таких ускладнень, як рецидиви захворювання, післяопераційні кровотечі та рубцеві стриктури анального каналу.

Отже, актуальність проблеми поєднаної патології анального каналу і прямої кишки спонукає до розробки і впровадження в клінічну практику нових високоефективних методів хірургічного лікування даної патології, які б забезпечували відсутність ускладнень в післяопераційному періоді і швидку медико-соціальну реабілітацію пацієнтів.
\end{abstract}

Ключові слова: поєднана аноректальна патологія; анальний канал; пряма кишка; сучасні методи хірургічного лікування; рубцева стриктура.

Поєднаній патології анального каналу і прямої кишки присвячена досить незначна кількість публікацій з результатами наукових досліджень, що зумовлено відсутністю єдиного підходу до вирішення даної проблеми.

Особливу увагу проктологів привертає наявність у пацієнтів поєднання анальної тріщини, ускладненої неповною внутрішньою норицею 3 хронічним гемороєм. Ряд авторів вважають методом вибору в такій ситуації висічення тріщини в межах здорових тканин із дозованою сфінктеротомією та гемороїдектомією [1]. Інші вважають необхідним після висічення тріщини виконувати сфінктеромукозопластику з гемороїдектомією [2]. Крім того, значну групу складають пацієнти 3 так званим “циркулярним” розташуванням гемороїдальних вузлів III-IV стадії в поєднанні 3 іншими захворюваннями анального каналу і прямої кишки, коли досягнення радикалізму операції $€$ ускладненим та іноді навіть неможливим через небезпеку розвитку рубцевих стриктур анального каналу [3]. До інших ускладнень після комбінованих операційних втручань на анальному кана- лі і прямій кишці з приводу їх поєднаної патології відносять недостатність анального сфінктера та грубі рубцеві деформації періанальних і параректальних ділянок, а також промежини [4].

При поєднаній патології анального каналу і прямої кишки одні автори рекомендують одноетапні операції, а інші $є$ прихильниками двохетапних операцій у хірургічному лікуванні цієї категорії пацієнтів. Однак більшість авторів є прибічниками одноетапних операційних втручань, вказуючи на такі переваги, як усунення в пацієнтів від двох і більше захворювань аноректальної ділянки, економічний ефект, пов’язаний із скороченням кількості ліжно-днів і відсутністю потреби в застосуванні тих самих медикаментів, відсутність негативного психологічного ефекту від другої операції для хворого, що має вплив на результат втручання і покращує якість життя пацієнтів [5].

Впродовж останнього десятиліття широкого застосування набули “гібридні” операції в лікуванні хронічного геморою III-IV стадії в комбінації з іншою патологією анального каналу i 
прямої кишки. Вони включають поєднання деартеріалізації гемороїдальних вузлів із мукопексією або латексне лігування гемороїдальних вузлів, їх ліфтинг та мукопексію з видаленням супутньої патології анального каналу [6, 7]. Ці операційні втручання значно покращують безпосередні та віддалені анатомічні та функціональні результати хірургічного лікування як геморою, так і супутньої аноректальної патології, але вони також, на жаль, не позбавлені недоліків. Серед ускладнень таких операцій спостерігають наступні: тромбоз зовнішнього гемороїдального вузла (2-5,7\%), гостра анальна тріщина (2 \%), післяопераційна кровотеча (1-2 \%), випадання гемороїдальних вузлів (6,6 \%), формування гіпертрофованих періанальних шкірних міток (75 \%) [8, 9].

У зв'язку із прогресивним розвитком сучасних технологій у практику колопроктологів почали швидко впроваджуватись сучасні методи хірургічного лікування аноректальної патології. Так, компанія "Valleylab” (США) розробила електротермічну систему "Liga Sure" для коагуляції і перетину судин у діаметрі до 7 мм, яку широко використовують для лікування геморою. В основі механізму впливу на тканини цієї системи лежить розплавлення колагену та еластину з формуванням щільної плівки за типом “завареної зони”, яка відмежовує рану від зовнішнього середовища, запобігаючи її інфікуванню. Крім того, немає необхідності в виділенні та лігуванні судинної ніжки гемороїдального вузла. Тому в літературі цей метод гемороїдектомії називають “закритою безшовною гемороїдектомією” [10, 11]. Але даний метод лікування має ряд недоліків: післяопераційні кровотечі (1,6-7,1\%), рубцеві стриктури анального каналу (2,1-2,9 \%) [12].

Широкого застосування в колопроктології набув ультразвуковий гармонічний скальпель "Ultra Cision” компанії Ethicon Endo-Surgery (США), принцип дії якого побудований на коливанні робочої насадки, що призводить до руйнування водневих сполук у білкових структурах колагену та їх склеювання. Внаслідок цього відбувається обтурація просвіту кровоносних судин до 3 мм у діаметрі. Глибина термічного впливу не перевищує 1,5 мм. Вказані властивості дають можливість проводити операційні втручання без прошивання судин із мінімальним термічним впливом на тканини анального каналу, що дозволяє зменшити тривалість операції та інтенсивність післяопераційного больового синдрому [13]. Однак цей метод супроводжується виникненням післяопераційних кровотеч (2,06-4 \%), а також збільшенням тривалості епітелізації післяопераційних ран вдвічі, порівняно з апаратом "Liga Sure" [14].

32005 р. почали широко використовуватись лазерні технології в лікуванні анальних тріщин та хронічного геморою. Застосування “лазерного скальпеля” базується на прямому механічному впливі високоінтенсивного опромінювання, яке дозволяє розрізати та “зварювати” тканини. Лазерне опромінювання інфрачервоною частиною спектра призводить до зменшення запальних змін у післяопераційних ранах, зниження больового синдрому, а також зменшення тимчасової непрацездатності на 2-3 доби [15]. Водночас із цим, дослідження із застосування лазера для гемороїдектомії показали, що цей метод супроводжується тривалим загоєнням післяопераційних ран, що, вірогідно, пов’язано з неконтрольованою глибиною термічного впливу, яка може складати до 4,2 мм та необхідністю додаткового прошивання крупних судин. Також відомо, що вуглекислотні лазери не володіють достатніми гемостатичними властивостями при наявності крові в операційній рані та здійснюють пряме проникнення інфрачервоної енергії в тканину, викликаючи ії̈ перегрів [16].

У зв'язку з прогресивним розвитком малоінвазивних методик лікування аноректальної патології все частіше зустрічаються відомості про застосування лазерної вапоризації анальної фістули та навколишніх тканин. Серед переваг даного методу лікування відмічається мінімізація больового синдрому в післяопераційному періоді, швидка епітелізація ран, а також можливість його застосування в амбулаторних умовах. Але цей метод лікування також супроводжується виникненням рецидивів анальної тріщини впродовж періоду спостереження від 1 до 3-х років 3 частотою 3,4$13,3 \%[17,18]$.

Викликає інтерес використання плазменного скальпеля в колопроктології. Принцип дії плазменного генератора базується на пропусканні інертного газу через електричний розряд, який виникає між двома електродами. При цьому відбувається іонізація газу (аргону) і утворення потоку плазми, який виходить із сопла маніпулятора. Коагуляція потоком плазми дозволяє заварювати судини в діаметрі до 6 мм, що забезпечує надійний гемостаз та дозволяє відмовитися від прошивання судин підслизового шару, скорочуючи тривалість операції. В 2009 р. О. М. Кузьмінов виконав дослідження з використанням плазменного скальпеля для хірургічного лікування геморою і було показано, що дана методика дозволяє знизити на 
16,7 \% частоту таких ускладнень, як дизуричні розлади та нагноєння ран, а також зменшити тривалість післяопераційного періоду. Але, на жаль, даний метод також не позбавлений недоліків, серед яких зустрічаються післяопераційні кровотечі (2,2 \%) та затримка сечовиділення (4,4 \%) [19].

Цікавим $є$ повідомлення про застосування 3 2011 р. у колопроктології апарата “En Seal” виробництва компанії Ethicon Endo-Surgery (США) для гемороїдектомії. Особливістю даного апарата $€$ здатність до біполярної електрокоагуляції тканин із вимірюванням імпедансу та одночасною дисекцією. Цей метод дозволяє виконувати стандартну “відкриту” гемороїдектомію без прошивання судинної ніжки. Серед ускладнень даної методики було виявлено виражений больовий синдром (2,1\%), стриктуру анального каналу (2,8 \%), кровотечу $(0,5 \%)$ [20].

Останнім часом все більше авторів рекомендують використовувати для хірургічного лікування аноректальної патології радіохвильовий скальпель “Surgitron" виробництва компанії Ellman International (США) . Принцип дії даного апарата полягає в атравматичному розрізі та коагуляції м'яких тканин за допомогою високочастотних радіохвиль, викликаючи в тканинах утворення тепла, під впливом якого відбувається розпад клітинних структур та їх випаровування і виникає ефект “розходження” тканин. При цьому теплове пошкодження тканин є мінімальним, а максимальна глибина коагуляційного некрозу складає 0,1-0,2 мм, що створює сприятливі умови для загоєння ран, а також сприяє зменшенню терміну їх загоєння, скороченню ліжко-днів та термінів непрацездатності хворих [21, 22].

У 2007 р. тайський професор Arun Rojanasakul запропонував методику LIFT (ligation of intersphincteric fistula tract), яка, за його даними, є ефективною більш ніж в 90 \% випадків незалежно від типу нориці. Але, на жаль, ця методика супроводжується виникненням рецидивів в 16,6-55,6 \% випадків, а також при її застосуванні в лікуванні транссфінктерних та екстрасфінктерних нориць прямої кишки виникає інтрасфінктерна нориця, яка потребує повторного операційного втручання [23].

Впродовж останнього десятиліття 3'явилось чимало публікацій про лікування нориць прямої кишки з використанням обтураторів - безклітинних матриксів для закриття норицевого ходу (PLUG) [24, 25]. В 2006 p. Johnson E. К. опублікував перші результати обтурації нориць прямої кишки ксенографтами, які являли собою гермети- зуючі тампони конусоподібної форми, що виготовлялися з колагену підслизового шару кишечника свиней і під впливом спеціальної обробки були позбавлені антигенних властивостей та були стійки до інфекційної агресії. Цей обтуратор мав волокнисту структуру і функціонував як колагенова матриця, яка сприяє швидкому закриттю норицевого ходу сполучною тканиною. Але частота рецидивів після застосування даної методики складає 8,8-14,28 \% [26].

Впродовж останніх років з'явилися повідомлення про використання фібринового клею в лікування прямокишкових нориць. У більшості випадків застосовували фібриновий клей Tissucol Fibrin Sealant, Baxter. Основними компонентами фібринового клею $є$ фібриноген, тромбін та іони кальцію, при змішуванні яких відбувається реакція згортання фібрину донорської плазми під впливом додатково введеного тромбіну, що забезпечує пломбування норицевого ходу і в подальшому сприяє міграції та активації фібробластів та формуванню колагенової структури. Але дана методика лікування нориць не отримала широкого практичного застосування у зв'язку з виникненням рецидивів з частотою 10-22 \% [27, 28].

Застосування в клінічну практику відеоендоскопічних технологій стало передумовою для розробки малоінвазивного високотехнологічного методу лікування нориць прямої кишки VAAFT (Video Assisted Anal Fistula Treatment). Дану методику розробив італійський хірург Piercarlo Meinero y 2011 p. [29]. Цей метод передбачає ушивання внутрішнього отвору нориці, фістулоскопію норицевого ходу з коагуляцією ділянок, які кровоточать після очищення його від сполучної тканини та прошивання слизової в ділянці попередньо ушитого внутрішнього отвору за допомогою лінійного або горизонтального степлера, надійно герметизуючи внутрішній отвір нориці. Але, на жаль, ця новітня технологія також супроводжується виникненням рецидивів нориці з частотою $12-16 \%$ [30].

Отже, актуальність проблеми поєднаної патології анального каналу і прямої кишки є досить високою і спонукає до розробки і впровадження в клінічну практику нових високоефективних методів хірургічного лікування даної патології, а також створення сучасних алгоритмів лікування цієї патології, які б забезпечували відсутність рецидивів та недостатності анального сфінктера в післяопераційному періоді і швидку медико-соціальну реабілітацію пацієнтів. 


\section{СПИСОК ЛІТЕРАТУРИ}

1. Тактика лечения больных с осложненными анальными трещинами / А. Б. Даценко, А. Я. Бардюк, А. В. Кириллов [и др.] // Материалы III Всероссийского съезда колопроктологов. - Белгород, 2011. - С. 26.

2. Опыт лечения анальной трещины в сочетании с хроническим геморроем / О. Р. Райымбеков, А. С. Бейшеналиев, Ж. М. Жолболдуев [и др.] // Материалы международного объединенного конгресса ассоциации колопроктологов России и первого ESCP/ECCO регионального мастер-класса // Колопроктология. - 2015. - № 1 (51) (приложение). - С. 42.

3. Черкасов М. Ф. Профилактика послеоперационных ослонений у больных хроническим комбинированным геморроем с “циркулярным” расположением геморроидальных узлов / М. Ф. Черкасов, А. А. Иванова, А. А. Помазков // Колопроктология. - 2011. - № 2 (36). - С. 33-38.

4. Шин И. П. Симультанные операции при заболеваниях аноректальной области / И. П. Шин, В. В. Павленко, А. В. Птахин // Материалы III Всероссийского съезда колопроктологов. - Белгород, 2011. - С. 59.

5. Хирургическое лечение сочетанной неопухолевой патологии анального канала и прямой кишки / А. В. Борота, Ф. И. Гюльмамедов, В. А. Гюльмамедов [и др.] // Колопроктология. - 2016. - № 4 (58). - С. 22-26.

6. Рафибеков Э. Д. HAL-RAR при лечении геморроя 3-4 стадии в сочетании с сопутствующей анальной патологией / Э. Д. Рафибеков, А. А. Субанов, А. А. Айсаев // Материалы II съезда колопроктологов стран СНГ, III съезда колопроктологов Украины с участием стран Центральной и Восточной Европы. - Одесса, 2011. - С. 504-505.

7. Белоцкая Л. В. Гибридные операции при хроническом геморрое / Л. В. Белоцкая, С. Ю. Чистохин // Материалы Всероссийского съезда колопроктологов с международным участием // Колопроктология. - 2016. - № 2 (56) (приложение). - С. 14.

8. Господарський А. Я. Хірургічне лікування геморою 3-4 стадії у поєднанні з хронічною анальною тріщиною / А. Я. Господарський, Р. В. Буратинський, Р. С. Древніцький // Матеріали IV з’їзду колопроктологів України // Клінічна хірургія. - 2016. - № 10.3 (893). - С. 86.

9. Досвід використання THD в комбінації з висіченням анальної тріщини / В. Ю. Пироговський, Б. В. Сорокін, Я. П. Фелештинський [та ін.] // Матеріали IV з’їзду колопроктологів України // Клінічна хірургія. - 2016. - № 10.3 (893). - С. 90 .

10. Применение аппарата “Ligasure” при оперативном лечении хронического геморроя / В. В. Дмитриченко, А. Е. Царегородцев, А. К. Ушкац // Материалы III Всероссийского съезда колопроктологов. - Белгород,2011. - С. 27.

11. Liga Sure hemorrhoidectomy: how we do it / G. Milito, G. Lisi, P. Sileri [et al.] // Colorectal Disease. - 2016. - Vol. 18, Issue 1. - P. 119.

12. Liga Sure versus conventional haemorrhoidectomy: a retrospective monocentric study / G. Milito, G. Lisi, P. Sileri [et al.] // Colorectal Disease. - 2016. - Vol. 18, Issue 1. - P. 119. 13. Гюльмамедов В. А. Использование ультразвукового скальпеля в хирургическом лечении геморроидальной болезни / В. А. Гюльмамедов // Материалы II съезда колопроктологов стран СНГ, ІІІ съезда колопроктологов Украины сучастием стран Центральной и Восточной Европы. - Одесса, 2011. - C. 422-423.

14. Тян Л. В. Лечение хронического парапроктита в сочетании с хроническим геморроем при помощи ультразвукового скальпеля / Л. В. Тян, Д. К. Туребаев, Д. П. Осипов //
Материалы III Всероссийского съезда колопроктологов.Белгород, 2011. - С. 32.

15. Salfi R. Lazer photocoagulation of haemorrhoidal arteries: a new outpatient technique / R. Salfi // Abstracts of XII Central European Congress of Coloproctology // Proctologia. - 2008. Vol. 9, Issue 1/08. - P. 117.

16. Haemorrhoids Laser Procedure (HeLP): early-anal longterm outcome in patient with II and III degree hemorrhoids / P. Giamundo, L. Esercizio, G. Fantino [et al.] // Colorectal Disease. - 2015. - Vol.17, Issue 2. - P. 33.

17. Is "laser" an option in the treatment of anal fistulas? Clinical results after closure of fistula-in-ano with diode laser / P. Giamunido, L. Esercisio, G. Fantino [et al.] // Colorectal. Disease. - 2015. - Vol. 17, Issue 2. - P. 32.

18. Giamundo P. Clinical long-term results of closure of fistulain-ano with diode laser (FiLaC) / P. Giamundo, M.Valente // Colorectal Disease. - 2016. - Vol. 18, Issue 1. - P.116.

19. Борисов И. Ф. Результаты геморроидэктомии плазменным скальпелем / И. Ф. Борисов, А. М. Кузьминов // Материалы III Всероссийского съезда колопроктологов. - Белгород, 2011. - С. 24.

20. Соловьёв О.Л. ОUT-PATIENT технология геморроидэктомии / О. Л. Соловьёв, А. О. Соловьёв, Г. А. Соловьёва // Материалы Всероссийского съезда колопроктологов с международным участием // Колопроктология. - 2016. - № 2 (56) (приложение). - С. 42.

21. Бродовський С. П. Малоінвазивні технології в хірургії анальних тріщин / С. П. Бродовський, В. В. Тарабанчук, Я. В. Бадовська // Матеріали IV з’їзд колопроктологів України // Клінічна хірургія. - 2016. - № 10.3 (893). С. 83-84.

22. Vivaldi C. Radiofrequency ablation of haemorrhoids:first results of a new technique / C. Vivaldi, H. Shaefer // Colorectal Disease. - 2016. - Vol.18, Issue 1. - P. 124.

23. LIFT procedure for perianal fistulas: risk factors for failure / G. V. Mijnsbrugge, C. Deen-Molenar, D. Ho [et al.] // Colorectal Disease. - 2016. - Vol.18, Issue 1. - P.17.

24. Sphincter-saving treatment of primary anal fistula with a new Acellular Dermal Matrix (ADM)plug: prospective study / G. Giarratano, C. Toccana, V. M. Stolfi [et al.] // Colorectal Disease. - 2015. - Vol.17, Issue 2. - P. 33.

25. Complex anal fistula treatment with bioabsorble synthetic anal fistula plug / F. Pakravan, C. Helmes, R. Fazlalizadeh [et al.] // Colorectal Disease. - 2015. -Vol. 17, Issue 2. - P. 97.

26. Acellular dermal matrix plug (Pressfit) in the treatment of primary transsphincteric anal fistula: a prospective study / G. Giarratano, E. Toscana, E. Giustozzi [et al.] // Colorectal Disease. - 2016. - Vol.18, Issue1. - P.116-117.

27. Seton drainage and fibrin glue injection for complex anal fistulas / V. De Parades, H. S. Far, J. Etienney // Colorectal Disease. - 2010. - Vol.12, Issue 4. - P. 459.

28. Опыт хирургического лечения сложных форм прямокишечных свищей с применением фибринового клея / В. Н. Эктов, Р. В. Попов, Н. Н. Коротких [и др.] // Материалы III Всероссийского съезда колопроктологов. - Белгород, 2011. - C. 59.

29. Video assisted anal fistula treatment (VAAFT) / P. Meinero, M. La Torre, A. Stazy [et al.] // Colorectal Disease. - 2015. Vol. 17, Issue 2. - P. 8.

30. Video-assisted anal fistula treatment (VAAFT) in criptoglandular fistula-in-ano: a systematic review and metaanalysis / P. Gard, M. K. Gard, A. Porwal [et al.] // Colorectal Disease. 2016. - Vol.18, Issue 1. - P. 29. 


\section{REFERENCES}

1. Datsenko, A.B., Bardyuk, A.Ia., Kirillov, A.V., Sedak, V.V., \& Bogun E.A. (2011). Taktika lecheniya bolnykh s oslozhnennymi analnymi treshchinami [Tactics of treatment of patients with complicated anal fissures]. Proceedings of the III All-Russian Congress of Coloproctologists. Belgorod, October 12-14. 2011. (p.26). Koloproktologiya - Coloproctology, 3 (37) [in Russian]. 2. Raiymbekov, O.R., Beyshenaliev, A.S., Zholbolduev, Zh.M., \& Attokurov, B.K. (2015). Opyt lecheniya analnoy treshchiny $\mathrm{v}$ sochetanii $\mathrm{s}$ khronicheskim gemorroyem [Experience in the treatment of anal fissure in combination with chronic hemorrhoids]. Proceedings of the International Joint Congress of the Association of Coloproctologists of Russia and the First ESCP / ECCO Regional Master Class. Moscow, April 16-18. 2015. (p.43). Koloproktologiya - Coloproctology, 1 (51) [in Russian]. 3. Cherkasov, M.F., Ivanova, A.A., \& Pomazkov, A.A. (2011). Profilaktika posleoperatsionnykh osloneniy u bolnykh khronicheskim kombinirovannym gemorroem s «tsirkuliarnym» raspolozheniem gemorroidalnykh uzlov [Prevention of postoperative disorders in patients with chronic combined hemorrhoids with a "circular" arrangement of hemorrhoids]. Koloproktologiya - Coloproctology, 2 (36), 33-38 [in Russian]. 4. Shin, I.P., Pavlenko, V.V., \& Ptakhin, A.V. (2011). Simultannye operatsii pri zabolevaniuyakh anorektalnoi oblasti [Simultaneous surgery for diseases of the anorectal region]. Proceedings of the III All-Russian Congress of Coloproctologists. Belgorod, October 1214. 2011. (p.59). Coloproctology, 3 (37) [in Russian].

5. Borota, A.V., Giulmamedov, F.I., Giulmamedov, V.A., Polunin, G.E., Plakhotnikov, I.A., \& Shalamov, V.I. (2016). Khirurgicheskoe lechenie sochetannoy neopukholevoy patologii analnogo kanala $i$ pryamoy kishki [Surgical treatment of combined non-tumor pathology of the anal canal and rectum]. Koloproktologiya - Coloproctology, 4 (58), 22-26 [in Russian]. 6. Rafibekov, E.D., Subanov, A.A., \& Aisaev, A.A. (2011). HAL-RAR pri lechenii gemorroia 3-4 stadii $v$ sochetanii $\mathrm{s}$ soputstvuyushchei analnoy patologiyey [HAL-RAR in the treatment of hemorrhoids 3-4 stages in combination with concomitant anal pathology]. Proceedings of the 2nd congress of coloproctologists of the CIS countries, the III Congress of Coloproctologists of Ukraine with the participation of the countries of Central and Eastern Europe. Odessa, May 18-20. 2011. (pp. 504-505). Kyiv: Publish centre Image of Ukraine [in Russian].

7. Belotskaya, L.V., \& Chistokhin, S.Yu. (2016). Gibridnye operatsii pri khronicheskom gemorroe [Hybrid surgery for chronic hemorrhoids]. Proceedings of the All-Russian congress of coloproctologists with international participation. Astrakhan, August 25-27. 2016. (pp. 14-15). Koloproktologia Coloproctology, 2 (56) [in Russian].

8. Hospodarskyi, A.Ia., Buratynskyi, R.V., \& Drevnitskyi, R.S. (2016). Khirurhichne likuvannia hemoroiu 3-4 stadii u poiednanni $\mathrm{z}$ khronichnoiu analnoiu trishchynoiu [Surgical treatment of 3-4 stages of hemorrhoids combined with chronic anal fissure]. Proceedings of IV congress of coloproctologists of Ukraine. Kyiv, October 26-28. 2016. (p.86). Klinichna khirurhiia - Clinical Surgery, 10.3(893 [in Ukrainian].

9. Pyrohovskyi, V.Iu., Sorokin, B.V., Feleshtynskyi, Ia.P., Zadorozhniy, S.P., Taranenko, A.O., Zlobenets, S.O., ... Noies, A.J. (2016). Dosvid vykorystannia THD v kombinatsii z vysichenniam analnoi trishchyny [Experience of using THD in combination with excision of the anal fissure]. Proceedings of IV congress of coloproctologists of Ukraine. Kyiv, October 26-28. 2016. (p.90) Klinichna khirurhiia - Clinical Surgery, 10. 3(893) [in Ukrainian].
10. Dmitrichenko, V.V., Tsaregorodtsev, A.E., Ushkats, A.K., \& Pogosyan, H.N. (2011). Primenenie apparata "Ligasure" pri operativnom lechenii khronicheskogo gemorroya [The use of the equipment "Ligasure" in the surgical treatment of chronic hemorrhoids]. Proceedings of the III All-Russian Congress of Coloproctologists. Belgorod, October 12-14. 2011. (p.27). Koloproktologiya - Coloproctology, 3 (37) [in Russian].

11. Milito, G., Lisi, G., \& Sileri, P. (2016). Liga Sure hemorrhoidectomy: how we do it. Colorectal Disease, 18, 119. 12. Milito, G., Lisi, G., \& Sileri, P. (2016). Liga Sure versus conventional haemorrhoidectomy: a retrospective monocentric study. Colorectal Disease, 18, 119.

13. Giulmamedov, V.A. (2011). Ispolzovanie ultrazvukovogo skalpelya $\mathrm{v}$ khirurgicheskom lechenii gemorroidalnoy bolezni [Use of an ultrasound scalpel in the surgical treatment of hemorrhoidal disease]. Proceedings of the 2nd congress of coloproctologists of the CIS countries, the III Congress of Coloproctologists of Ukraine by the participation of the countries of Central and Eastern Europe. Odessa, May 18-20. 2011. (pp. 422-423). Kyiv: Publish centre Image of Ukraine [in Russian].

14. Tian, L.V., Turebaev, D.K., \& Osipov, D.P. (2011). Lechenie khronicheskogo paraproktita $\mathrm{v}$ sochetanii s khronicheskim gemorroem pri pomoshchi ultrazvukovogo skalpelia [Treatment of chronic paraproctitis in combination with chronic hemorrhoids by using an ultrasound scalpel]. Proceedings of the III All-Russian Congress of Coloproctologists. Belgorod, October 12-14. 2011. (p.32). Koloproktologiya - Coloproctology, 3 (37) [in Russian]. 15. Salfi, R. (2008). Lazer photocoagulation of haemorrhoidal arteries: a new outpatient technique. Proceedings of XII Central European Congress of Coloproctologists. Moscow, May 6-8. 2008. Proctologiya - Proctology, 9 (1/08), 117.

16. Giamundo, P., Esercizio, L., \& Fantino, G. (2015). Haemorrhoids laser procedure (HeLP): early-anal long-term outcome in patient with II and III degree hemorrhoids. Colorectal Disease, 17 (2), 33.

17. Giamunido, P., Esercisio, L., \& Fantino, G. (2015). Is “laser” an option in the treatment of anal fistulas? Clinical results after closure of fistula-in-ano with diode laser. Colorectal. Disease, 17(2), 32.

18. Giamundo, P., \& Valente, M. (2016). Clinical long-term results of closure of fistula-in-ano with diode laser (FiLaC). Colorectal Disease, 18 (1), 116.

19. Borisov, I.F., \& Kuzminov, A.M. (2011). Rezultaty gemorroidektomii plazmennym skalpelem [Results of hemorrhoidectomy with a plasma scalpel]. Proceedings of the III All-Russian Congress of Coloproctologists. Belgorod, October 12-14. 2011. (p.24). Koloproktologiya - Coloproctology, 3 (37) [in Russian].

20. Solovev, O.L., Solovev, A.O., \& Soloveva, G.A. (2016). OUT-PATIENT tekhnologiia gemorroidektomii [OUTPATIENT technology of hemorrhoidectomy]. Proceedings of the All-Russian congress of coloproctologists with international participation. Astrakhan, August 25-27. 2016. (pp. 42-43). Koloproktologiya - Coloproctology, 2 (56) [in Russian].

21. Brodovskyi, S.P., Tarabanchuk, V.V., \& Badovska, Ia.V. (2016). Maloinvazyvni tekhnolohii v khirurhii analnykh trishchyn [Minimal invasive technologies in anal fissure surgery]. Materials of IV congress of coloproctologists of Ukraine. Kyiv, October 2628. 2016. (pp. 83-84). Klinichna khirurhiia - Clinical Surgery, 10.3(893 [in Ukrainian].

22. Vivaldi, C., \& Shaefer, H. (2016). Radiofrequency ablation of haemorrhoids:first results of a new technique. Colorectal Disease, 18 (1), 124. 
23. Mijnsbrugge, G.V., Deen-Molenar, C., Ho, D., Jordanov, T., \&Felt- Bersma, R. (2016). LIFT procedure for perianal fistulas: risk factors for failure. Colorectal Disease, 18 (1), 17.

24. Giarratano, G., Toccana, C., Stolfi, V.M., Franceschilli, L., Sileri, P., \& Toscana,E. (2015). Sphincter-saving treatment of primary anal fistula with a new Acellular Dermal Matrix (ADM) plug: prospective study. Colorectal Disease, 17 (2), 33.

25. Pakravan, F., Helmes, C., Fazlalizadeh, R., \& Heydari, A. (2015). Complex anal fistula treatment with bioabsorble synthetic anal fistula plug. Colorectal Disease, 17 (2), 97.

26. Giarratano, G., Toscana, E., Giustozzi, E., Mohamed, S., Sileri, P., \& Toscana, C. (2016). Acellular dermal matrix plug (Pressfit) in the treatment of primary transsphincteric anal fistula: a prospective study. Colorectal Disease, 18 (1), 116-117.

27. De Parades, V., Far, H.S., \& Etienney, J. (2010). drainage and fibrin glue injection for complex anal fistulas. Colorectal
Disease, 12 (4), 459.

28. Ektov, V.N., Popov, R.V., Korotkikh, N.N., \& Vollis, E.A. (2011). Opyt khirurgicheskogo lecheniya slozhnykh form pryamokishechnykh svishchey s primeneniyem fibrinovogo kleya [The experience of surgical treatment of complex forms of rectal fistula using fibrin glue]. Proceedings of the III AllRussian Congress of Coloproctologists. Belgorod, October 1214. 2011. (p.59). Koloproktologiya - Coloproctology, 3 (37) [in Russian].

29. Meinero, P., LaTorre, M., Stazy, A., \& Carbone, A. (2015). Video assisted anal fistula treatment (VAAFT). Colorectal Disease, 17(2), 8.

30. Gard, P., Gard, M.K., Porwal, A., Singh, P., \& Singh, S. (2016). Video-assisted anal fistula treatment (VAAFT) in criptoglandular fistula-in-ano: a systematic review and metaanalysis. Colorectal Disease, 18 (1), 29.

\title{
M. P. ZAKHARASH ${ }^{1}$, V. V. BALYTSKYY ${ }^{2,3}$, O. G. KURYK ${ }^{4}$
}

O. Bohomolets National Medical University, Kyiv ${ }^{1}$

M. Pyrohov Vinnytsia National Medical University ${ }^{2}$

Khmelnytskyi Regional Hospital ${ }^{3}$

State Scientific Institution "Scientific-Practical Centre of Preventive and Clinical Medicine" State Administration of Affairs, Kyiv ${ }^{4}$

\section{MODERN METHODS OF SURGICAL TREATMENT OF COMBINED ANAL AND RECTAL PATHOLOGY}

\begin{abstract}
The urgency of the problem of combined anorectal pathology is quite high, which have caused today by fast grown number of proctological diseases and absence of single direction for surgical treatment of this category of patients. Besides, there are rather insignificant number of publications with results of scientific researches, which are devoted to studying of this problem. Scar strictures of the anal canal, insufficiency of anal sphincter and also deformations of perianal and pararectal regions and perineum are the most often found among of the complications after combined operations on the anal canal and rectum due to their combined pathology. During the last ten years the "hybrid" operations for treatment of III-IV degrees of chronic haemorrhoids with combination of another anal and rectal pathology are widespread. They include the combination of haemorrhoidal dearterialization with mucopexy or rubber band ligation of haemorrhoids, their lifting and mucopexy with another anal pathology removal. According to progressive development of modern technologies in proctological practice such modern methods of surgical treatment of anorectal pathology as electrothermic system "Liga Sure”, ultrasound harmonic scalpel "Ultra Cision”, laser technologies for treatment of anal fissures, chronic haemorrhoids and fistulas (LHP, FiLaC), plasma scalpel, bipolar system“En Seal”, radiowave scalpel "Surgitron” and also methods LIFT (ligation of intersphincteric fistula tract) and VAAFT (Video Assisted Anal Fistula Treatment) have been fast established, which have made less the lasting of operations, volume of bleeding, intensity of the pain syndrome, but, unfortunately, did not exclude such complications as disease recurrences, postoperative bleedings and scar strictures of the anal canal.

So, the urgency of the problem of combined pathology of anal canal and rectum induces to elaboration and establishment new high effective methods of surgical treatment of this pathology in clinical practice, which will provide the absence of complications in postoperative period and the fast medical and social patients rehabilitation.
\end{abstract}

Key words: combined anorectal pathology; anal canal; rectum; modern methods of surgical treatment; stricture.

\section{М. П. ЗАХАРАШ ${ }^{1}$, В. В. БАЛИЦКИЙ ${ }^{2,3}$, Е. Г. КУРЫК ${ }^{4}$}

Национальный медицинский университет имени А. А. Богомольца, Киев ${ }^{1}$ Винницкий национальный медицинский университет имени Н. И. Пирогова 2 Хмельницкая областная больница,

Государственное научное учреждение "Научно-практический центр профилактической и клинической медицины” Государственного управления делами, Киев ${ }^{4}$

\section{СОВРЕМЕННЫЕ МЕТОДЫ ХИРУРГИЧЕСКОГО ЛЕЧЕНИЯ СОЧЕТАННОЙ ПАТОЛОГИИ АНА.ЛЬНОГО КАНАЛА И ПРЯМОЙ КИШКИ}

Актуальность проблемы сочетанной патологии анального канала и прямой кишки является очень высокой, что обусловлено на сегодняшний день стремительно увеличивающимся количеством проктологических заболеваний, а также отсутствием единого подхода к хирургическому лечению этой категории пациентов. Кроме того, изучению данной проблемы посвящено очень 
незначительное количество публикаций с результатами научных исследований. Среди осложнений после комбинированных оперативных вмешательств на анальном канале и прямой кишке по поводу их сочетанной патологии наиболее часто встречаются рубцовые стриктуры анального канала, недостаточность анального сфинктера, а также грубые рубцовые деформации перианальных и параректальных областей и промежности. На протяжении последнего десятилетия широкое применение приобрели “гибридные” операции в лечении хронического геморроя III-IV стадии в комбинации с другой патологией анального канала и прямой кишки. Они включают сочетание деартериализации геморроидальных узлов с мукопексией или латексное лигирование геморроидальных узлов, их лифтинг и мукопексию с удалением сопутствующей патологии анального канала В связи с прогрессивным развитием современных технологий в практику колопроктологов начали быстро внедряться такие современные методы хирургического лечения аноректальной патологии, как электротермическая система система “Liga Sure”, ультразвуковой гармонический скальпель “Ultra Cision”, лазерные технологии в лечении анальных трещин, хронического геморроя и парапроктита (LHP, FiLaC), плазменный скальпель, биполярная система“En Seal”, радиоволновой скальпель “Surgitron”, а также методики LIFT (ligation of intersphincteric fistula tract) и VAAFT (Video Assisted Anal Fistula Treatment), которые уменьшили продолжительность операций, объём кровопотери, интенсивность болевого синдрома, но, к сожалению, не сумели лишить пациентов таких осложнений, как рецидивы заболевания, послеоперационные кровотечения и рубцовые стриктури анального канала.

Таким образом, актуальность проблемы сочетанной патологии анального канала и прямой кишки побуждает к разработке и внедрению в клиническую практику новых высокоэффективных методов хирургического лечения данной патологии, которые обеспечивали бы отсутствие осложнений в послеоперационном периоде и быструю медико-социальную реабилитацию пациентов.

Ключевые слова: сочетанная аноректальная патология; анальный канал; прямая кишка; современные методы хирургического лечения; рубцовая стриктура. 